\title{
Education On-Line: What's In It For Women?
}

\author{
HELEN J. RICHARDSON and SHEILA FRENCH \\ U. of Salford,H.Richardson@salford.ac.uk, \& City College, Manchester, sfrench@ccm.ac.uk
}

\begin{abstract}
UK government policies are heralding the use of ICT's in education with the hope that on-line learning will bring skill development attractive to industry and improved employment opportunities for today's learners. One feature of this is increasing the use of technology in teaching and learning across the curriculum. In this atmosphere of euphoria and expectation, is this opportunity for all or just a few? There has been little empirical work on the gender impact of using technology in education. This paper takes a case study approach and critically evaluates an on-line course developed for IT undergraduate students at the University of Salford, as part of a major flexible learning initiative. Our research raises many questions. Why should women students be motivated to learn using technology? Previous studies have suggested that boys show a marked improvement when using educational technology to support their learning. For girls the results are much less clear. In this context we questioned the gender impact of an increased use of technology in the teaching and learning process. We investigated the gender divide in attitudes, and effects on learning outcomes, within the initiative. We also discuss our evaluation methodology that included gender impact elements and suggest ways in which to create a woman-friendly on-line learning environment.
\end{abstract}

\section{INTRODUCTION}

It is recognised that gender differences in attitudes to technology exist. Although the first computer programmers were women [17], Wajcman [21] claims that today men have the monopoly on technology and suggests that social influences have contributed to the lack of technical confidence or competence becoming part of the feminine identity. Griffiths [9] goes further suggesting that women are now excluded from technology, but not always against their will. 
Computing has a 'male image.' NCET [14] maintain that the reasons for this includes our social culture, influences at home, role models and the school environment. The main users of computer games are boys and the main characters in the games are male [3]. Many girls are put off by computers because of violent and immature games, with girls adopting an attitude of 'we can but we won't' [19]. Girls have strong preferences to the type of software they are using and this means that unless they like the software they lose interest and their performance drops [10]. Socialisation is also important with parents and teachers considering learning tools to be for males' [22]. One school found that when using ICT's to teach languages, their male pupils performance improved whilst the female pupils performance remained the same [4].

By the year $2000,80 \%$ of jobs will involve the use of ICT's, but women are declining to take IT at university [19]. Selby et al. [18] conclude that women lack knowledge of IT and computing as a career, have an image of computer science as nerdy, geeky, anti-social, machine-orientated, mathematical and solitary. IT degrees also often have inadequate teaching and learning environments with teaching methods alien to women's preferred learning styles $[18,20]$.

\section{WOMEN AT WORK IN COMPUTING AND I.T.}

The UK IT industry is male orientated with women making up only $22 \%$ of those in the profession [14]. The representation of women is falling, gender segregation pervades, and the numbers of women decline the further up the hierarchy you go [16]. Industry and education are concerned about the low numbers of women participating in computing and IT because of the impact on industry and society as a whole. Computer competence is not just another occupational or leisure-time preference:

"The fact that women have practically no voice in the creation of major technological innovations that control our lives is surely to the detriment of the industry and society as a whole" $[18, \mathrm{p} .6]$.

We may already have reason to question whether women will choose to use technology as a tool to learn with and we certainly should be aware it might not be their first choice. This also presupposes that a choice will be available. 


\section{EDUCATION AND PEDAGOGY}

Von Prummer [20] notes that open or distance learning is often heralded as being a good way for women to get an education because there is little or no attendance requirement and a lot of flexibility in learning schedules and time management. Mothers have no fixed schedule (allegedly) and therefore could fit study around family commitments. Parallel research $[20,11]$ however, found that the learning style imposed by distance learning did not suit many women. They found that women generally prefer 'social learning' and conclude that often women have to adapt to the system available. Less contact with tutors and other students can push women's education into their private worlds rather than bringing them into public spheres [6]. Some women face a great deal of domestic pressure when in education and are more likely to have to try to balance study, work and home responsibilities [13]. On-line courses can exacerbate domestic tensions for women and clearly:

"no open learning pack or distance learning course minds the children, cleans the toilets and does the ironing; rather these educational incursions into the home add further demands which can be very difficult to reconcile with existing home activities." [6, p.53]

Maynard and Pearsall [13] found that student mothers often felt they had to reassure the family of the minimal repercussions their studies would have on family life in order to get approval. Relationships were threatened because of conflicts between study and domestic commitments and also the changing identity of the student. Women had to resolve feelings of guilt at not performing the domestic role as well as before, whereas mature male students found it easier to opt out of parenting and other domestic responsibilities.

Kirkup and Abbot [11] discuss access to a computer in the home with women students feeling that the home computer is a family resource and their study requirements are not a priority. Women often feel guilty about spending money on a computer rather than their family [2]. Maynard and Pearsall [13] agree, noting that women often have no specified study time or study area at home compared to men, whose study needs go to the top of the domestic agenda.

There are many issues related to gender and extrinsic and intrinsic motivations of study [8, 12, 22]. Men more generally have extrinsic motivation concerned about the qualifications they will achieve. Women are more concerned with achieving personal satisfaction and so issues like course content and other intrinsic aspects are important to them. Greasley [8] 
shows that women tend to spend more time preparing for study and are motivated by fear of failure.

Von Prummer [20] urges us to look at the climate of the institution - if women students have to consult male lecturers, professors and tutors every step of the way, then this gives a clear message. Teaching materials can also be biased, as has been identified in relation to educational software in schools [3].

\section{CASE STUDY: IMPLEMENTING FLEXIBLE LEARNING.}

These issues were firmly in the minds of the authors when they embarked on a major flexible learning initiative within an IT department at the University of Salford. The idea to introduce flexibility came in the context of sharing resources and making full use of IT facilities without adversely affecting teaching and learning outcomes or the whole university experience for students.

This Case Study considers the development of one of the undergraduate degree modules as a flexible learning resource. The initiative involved providing paper-based and on-line material, some lectures (voluntary attendance) and some assignment deadlines to be met, but generally allowing flexibility in how the module was studied, in terms of where and when.

There is some background information about the degree that will be useful to the reader. Teamwork is a major feature of the degree programme. The degree requires a high level of attendance because of group and practical work. There are lots of early starts and late finishes and so it is not a family friendly learning environment.

We implemented flexible learning into a mandatory first year module called 'Electronic Information Services' (EIS). It has three basic sections - a research element, a web page design element and a group presentation. We were aware of the low proportion of women students compared to men, taking the IT degree. In 1998, the gender distribution was $18 \%$ women and $82 \%$ men. We felt that issues of access to a computer at home, the outside commitments of women students in particular and the potentially different learning approaches of men and women would impact on our project.

\subsection{Implementation framework}

An implementation framework was devised based on a continuous improvement loop of planning the learning, implementing, using technology where appropriate, evaluating the module and then making improvement [7]. 
Changes to learning materials were pedagogically rather than technology driven. The learning materials and assessment strategy were all planned around the framework and considerable support mechanisms were built in to suit the needs of the flexible learner. Gender differences were considered during implementation and our evaluation methodology looked at gender impacts.

\subsection{Support mechanisms}

There were a variety of support mechanisms available. An advice and discussion forum was set up, soon to be known as the Virtual Seminar, in newsgroup style. Issues and problems were raised here and the lecturer ensured rapid response to specific questions. Students had ready access by email to each other and to the lecturer. Section lectures, workshops and tutorials were held regularly. Students were encouraged to ask detailed technical questions and also raise very basic issues so the different levels of skills, ability, knowledge and confidence were recognised. This fostered a supportive learning environment. Students could also use their multi-year team project members as sources of help and advice.

\subsection{The evaluation methodology}

Our evaluation methodology aimed to assess and improve the effectiveness of the EIS module and to identify the influences and affects of various contextual factors including gender differences as part of the loop in the framework. To summarise, issues included:

Flexibility and access: motivation to use the on-line materials, usability issues and preferences for paper-based or on-line media; study times and preparation; attitudes to using technology in learning and also to different aspects of the module; where students studied; access to technology at university and at home.

Teaching, learning and support: where students got support from; did students work together or individually; the impact of having a female lecturer.

Learning outcomes: any gender differences in achievement and within different sections of the module.

It was also important to create student profiles, understanding the students in their context of previous experience, motives, personal factors and learning styles.

The evaluation had a mixture of formative and summative elements using a volunteer focus group. We were aware of the problems of only asking for volunteers to help with evaluation and creating an unrepresentative sample. 
Also selecting a group can create a feeling of preferential treatment [5]. So we used both volunteers for the focus group and involved the whole group in a substantial summative questionnaire. The focus group consisted of $40 \%$ women and $60 \%$ men and the summative questionnaire was completed in a ratio of $25 \%$ women and $75 \%$ men. The evaluator guided the taped sessions with a number of open questions and areas of discussion planned. The lecturer also kept a logbook of emails and help required by the students who she had contact with. The module assessment was used as a measure against achievement of learning outcomes.

\section{OUR FINDINGS}

\subsection{Flexibility and access:}

Students liked the fact that they could work at their own pace and complete the required work when and where they could. Many male and female students had outside commitments including working long hours and having caring and family responsibilities. The men however, reported that this did not affect their studies. There were gender differences in study time. We found that men in general studied at various times of the day with their main time being from $4-8 \mathrm{pm}$, whereas the majority of women studied late into the evening fitting study around other commitments. Most of the students had access to computers outside of the university. Students often had to share resources with other family members or friends and did not have priority access. Women in particular faced computer access problems both at home and at university. We found that both men and women used online and paper-based materials. Women spent a lot more time than the men in preparation for the module. Despite equal qualifications and experience prior to the module, women were much more apprehensive than the men about their ability. Women liked all three aspects of the module equally whereas the men substantially enjoyed web page design, many boasting about their expertise.

\subsection{Teaching, learning and support}

Gender differences emerged in the support mechanisms utilised by students. Women mainly e-mailed friends or the lecturer for support. Male students e-mailed their friends and also in equal numbers used their team project members. No women used this method of support. This gives cause for concern and further research is needed. Both men and women students 
welcomed contact with the lecturer, interaction with other students and cooperation with other learners. The lecturer also answered a substantial number of e-mail questions that included specific queries and also the raising of personal and domestic problems. The majority of the women had joined a study group - both women only and mixed - and this was particularly evident with the mature women students. Focus group discussion concluded that women lecturers were more approachable than men were.

\subsection{Learning outcomes}

The confidence that more of the men felt and the apprehension that many of the women felt was not substantially reflected in the grades they achieved. The men achieved slightly higher grades than the women as a whole on the web page design assessment. Women overall were concentrated at the top end of the grades for all assessed work. Overall, our evaluation showed that students were very happy with the module and its delivery.

\section{CREATING A WOMAN-FRIENDLY ON-LINE LEARNING ENVIRONMENT}

Our findings have highlighted many areas that need improvement in order to create a woman-friendly on-line learning environment. Women can be isolated without the same peer support as men. Women in particular have commitments outside study and may face difficulties working at home. Online learning needs to offer a variety of media, support mechanisms and interaction with other learners and tutors.

We have highlighted concerns that women may not be motivated to use technology in education and this needs to inform government policy. Clearly young women and mature women students can be successful in pursuing IT as a degree. The challenge is to persuade women to choose this pathway rather than encouraging them to take their talents elsewhere. Flexible learning in general needs to take into account the support mechanisms necessary, resources needed, gender impacts and address computer access issues.

\section{REFERENCES}

1. Bain, A., Hess, P.T., Jones, G., Berelowitz, C. (1999). Gender differences and computer competency: The effects of a high access computer program on the computer competence of young women. http://www.outreach.uiuc.edu/ijet/v1n1/bain/index.html 
2. Broadhurst, J. (1997). Gender differences in Online Communication in Ermann, M.D., Williams, M.B., Shauf, M.S. Computers, Ethics and society, 2nd Ed. Oxford University Press.

3. Clarke, A. (1999). University for industry IT sector modeling. NIACE - DfEE.

4. educ@guardian. (1998). Tuesday October 13th 1998.

5. Evaluation cookbook (1999). (various authors), Learning Technology Dissemination Initiative. Heriot-Watt university. http://www.icbl.hw.ac.uk/ltdi.

6. Evans, T. (1994). Understanding Learners In Open And Distance Education. London: Kogan Page.

7. French, S. (1998). Implementing flexible learning. Unpublished paper: IT Institute. University of Salford.

8. Greasley, K. (1998). Does gender affect students' approaches to learning? In. S. Brown, S. Armstrong and G. Thompson. (Eds), Motivating students. Edgbaston, Kogan Page SEDA.

9. Griffiths, D. (1985). The exclusion of women from technology, in Smothered by invention. W. Faulkner and E. Arnold. (Eds.) Pp. 51-71.London: Pluto Press.

10. Joiner, R., Messer, D., Littleton, K., Light, P. (1996). Gender, computer experience and computer-based problem solving. Computer Education 26(1-3), 179-187.

11. Kirkup, G. and J. Abbott (1997). The gender gap. A gender analysis of the 1996 computing access survey. Milton Keynes, PLUM Paper number 80. (Programme on Learner Use of Media, Open University).

12. Magee, R., Baldwin, A., Newstead, S., Fullerton, H. (1998). Age, gender and course differences in approaches to studying in first-year undergraduate students, in Motivating Students. S. Brown, S. Armstrong and G. Thompson. (Eds.). Edgbaston: Kogan Page SEDA.

13. Maynard, E. M. and S. J. Pearsall (1994). What about male mature students? A comparison of the experiences of men and women students. Journal of Access Studies 9, 229-240.

14. NCET (1996). Gender and IT. Coventry.

15. Oliver, M. and G. Conole (1998). Evaluating communication and information technologies: a toolkit for practitioners. Active Learning 8.

16. Panteli, N. (1998). Review of 'Women computer professional: progress and resistance' by Rosemary Wright. Journal of Strategic Information Systems 7, 71-77.

17. Roberts, P. (1997). Androgynous Women and Computing: A Perfect match? (pp.102-112) In R. Lander and A. Adam (Eds.). Women in Computing. Exeter: Intellect Books.

18. Selby, L., Young, A., Fisher, D. (1997). Increasing the participation of women in tertiary level computing courses: what works and why. ASCILITE'97.

19. Siann, G. (1997). We can, we don't want to: Factors influencing women's participation in computing. In R. Lander and A. Adam (Eds.). Women in Computing. Exeter: Intellect Books.

20.von Prummer, C. (1994). Women-friendly perspectives in distance education. Open Learning 9(1).

21. Wajcman, J. (1991). Feminism Confronts Technology. Cambridge: Polity Press.

22. Wilson, F. (1997). Computing, computer science and computer scientists: how they are perceived. In R. Lander and A. Adam (Eds.). Women in Computing. Exeter: Intellect Books. 